\title{
Biomonitoring and Health Disparities - Emerging Opportunities
}

\author{
Clement Bezold
}

Institute for Alternative Futures

(C) 2007 Californian Journal of Health Promotion. All rights reserved.

The attached presentation entitled, "Biomonitoring and Health Disparities - Emerging Opportunities", was presented at Disparities in Health in America: Working Toward Social Justice, June 24-30, 2006, M D Anderson Cancer Center.

\section{Notes to Accompany Slides}

\begin{tabular}{|l|l|}
\hline \multicolumn{1}{|c|}{ Slides } & \multicolumn{1}{c|}{ Topic } \\
\hline $5-10$ & Introduction on Disparities and the DRA (Disparity Reducing Advances) Project \\
\hline $15-16$ & Challenge of biomonitoring: the "bathroom scale problem \\
\hline $17-27$ & Growth of biomonitoring - range of possible platforms for biomonitoring \\
\hline $28-37$ & $\begin{array}{l}\text { The diabetes epidemic; its tragedy and our mis aligned incentives (get paid to amputate a leg } \\
\text { but not inspect a foot and prevent the need for amputation.) Includes results of expose from } \\
\text { New York Times in January of 2006. }\end{array}$ \\
\hline $39-40$ & On the preventability of diabetes \\
\hline $48-58$ & Cancer and Biomonitoring \\
\hline $59-75$ & Biomonitoring for Prevention and Healthy Living \\
\hline 76 & DRA Project Recommendations for promoting biomonitoring as a disparity reducing advance \\
\hline 88 & DRA Project Criteria for a disparity reducing advance \\
\hline $89-91$ & The DRA Project in 2006 and 2007 \\
\hline
\end{tabular}

$\underline{\text { Author Information }}$

Clement Bezold, $\mathrm{PhD}$

Chairman of the Board and Founder

Institute for Alternative Futures

100 North Pitt Street, Suite 235

Alexandria, VA 22314

Ph.: 703-684-5880

Fax.: 703-684-0640

URL: http://www.altfutures.com

* corresponding author 


\section{Disparities Reducing Advances Project}

April 6, 2006 Alexandria, Virginia

\section{Biomonitoring and Health \\ Disparities - Emerging \\ Opportunities \\ Clement Bezold, Ph.D.}

\section{For}

Disparities in Health in America: Working Toward Social J ustice J une 24-30, 2006

M D Anderson Cancer Center

Institute for Alternative Futures

Disparities in Health in America:

Working Toward Social J ustice June 24-30, 2006

M D Anderson Cancer Center

Social J ustice - involves

-Understanding

-Changing minds and hearts

-Commitments, priorities \& action

Equity = an issue, like slavery and women's rights, where society is changing its mind

Biomonitoring Futures Project and the "DRA Project"

- These findings are from the "Biomonitoring Futures Project", funded by the Robert Wood Johnson Foundation, a component of of IAF's Disparity Reducing Advances Project

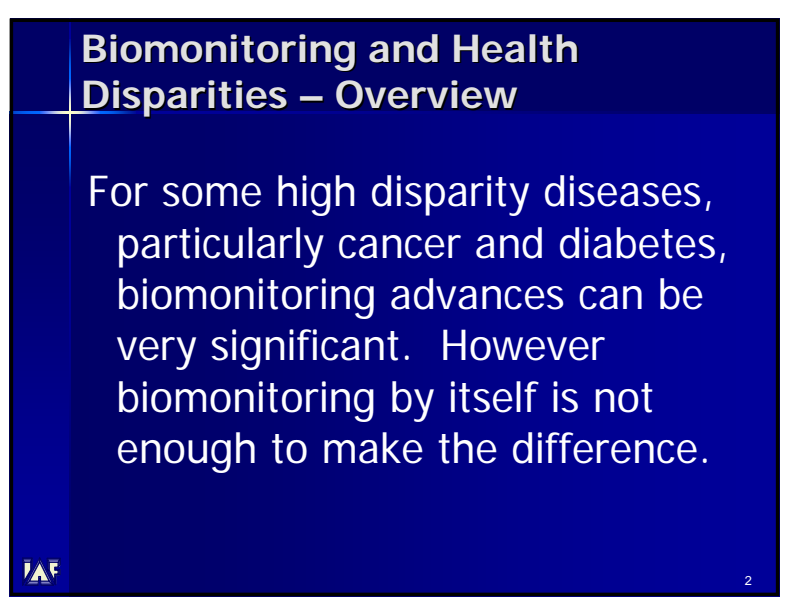

Biomonitoring and Health

Disparities - Topics

- The Biomonitoring Futures Project and the Disparity Reducing Advances Project

- Biomonitoring in the context of causes of disparities

- Cancer 2015; Diabetes 2015

- Advances in biomonitoring - diabetes, cancer and healthy living/prevention

- Accelerating biomonitoring as a disparity reducing advance
I AF's Disparity Reducing Advances Project

The DRA Project is a multi-year, multi-stakeholder project developed by the Institute for Alternative Futures (IAF) to identify and accelerate the most promising advances for bringing health gains to the poor and marginalized. 


\section{Disparities Reducing Advances Project}

April 6, 2006 Alexandria, Virginia

\section{DRA Project Sponsors}

National Cancer Institute, Center to Reduce Cancer Health Disparities

Agency for Healthcare Quality and Research

Robert Wood J ohnson Foundation

Florida Hospital

LAF

University of Texas Medical Branch

\section{DRA Project Partners}

-Institute for Alternative Futures

-Institute for Community Health -Institute for Healthcare Improvement

-Institute for the Elimination of Health Disparities at The University of Medicine and Dentistry of New Jersey

-Intercultural Cancer Council

-Leadership by Design, Inc.

-Maryland Department of Health and Mental Hygiene

-Medical Automation Research Center at the University

$$
\text { of Virginia }
$$

-Planetree

-Prevention Institute

-Resource Center for Health Policy at the University of Washington

Le

-Samueli Institute for Information Biology

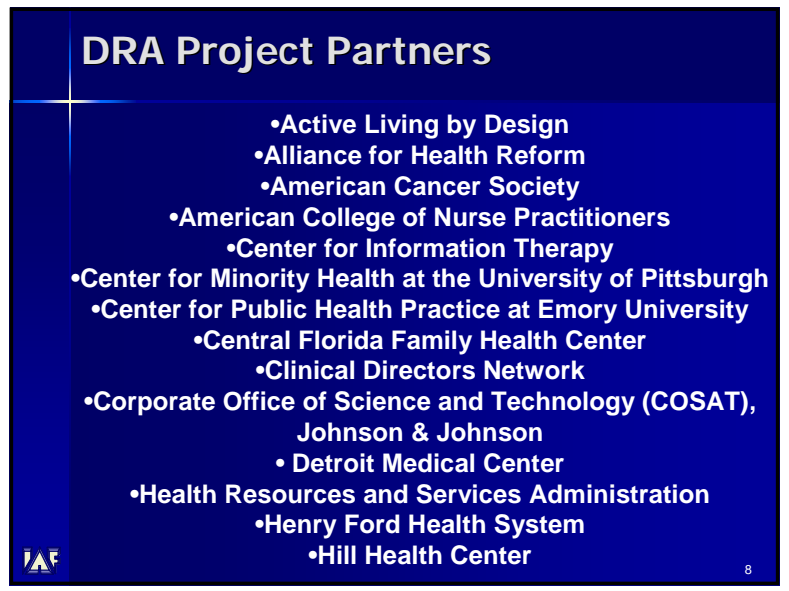

Your Organizations are welcome to join the DRA Project

- The information presented here is available at

- www.altfutures.com/dra

- $\underline{w w w . a l t f u t u r e s . c o m / b f p}$

- If you and your organization are interested in becoming a DRA Project Partner - contact Clem Bezold or Sandra Tinkham at IAF (stinkham@altfutures.com).

\section{Why the DRA Project Is I mportant}

- Health disparities are significant

- They are not perceived by most in the US

- Pursuit of equity (fairness) is a trend, like slavery and women's rights, that will take time and support, but can be accelerated

- Equity in: WHO Health For All, Healthy People 2010, IOM's Crossing the Chasm Report

- There will be advances - some of which can be identified and accelerated to reduce disparities

- The DRA Project, using us - the DRA Partner Network and those we affect - can do this.

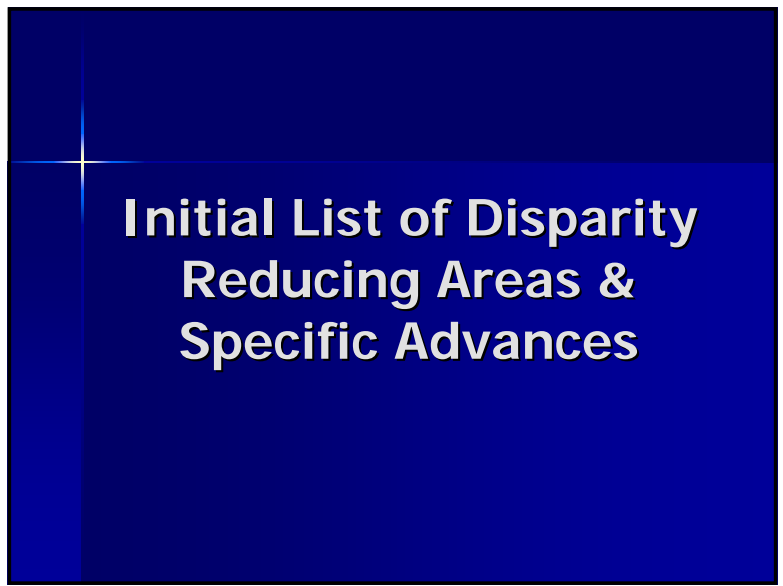




\section{Disparities Reducing Advances Project}

April 6, 2006 Alexandria, Virginia

I nitial Advance Areas to Consider

- Community health and prevention

- Better quality health care - More effective, caring treatment

- Complementary and alternative approaches

- Risk I dentification

- Biomonitoring/ Bioinformatics

- Behavior coaching/ reinforcement

$\overline{\mathbf{A}^{\mathbf{F}}}$

\section{When Biomonitoring is not enough}

- There is an important biomonitor that is inexpensive, easy to use, commonly availble. It provides important information on risk factors for cancer, diabetes, and a variety of other diseases. It also is important for managing diabetes.

- But is often ignored
LEF

\section{The Biomonitoring Futures Project}

- Biomonitoring is one area of disparity reducing advance. The Robert Wood Johnson Foundation has provided funding to consider the future applications of biomonitoring and its role in reducing health disparities.

- The BFP is a component of the larger DRA Project.
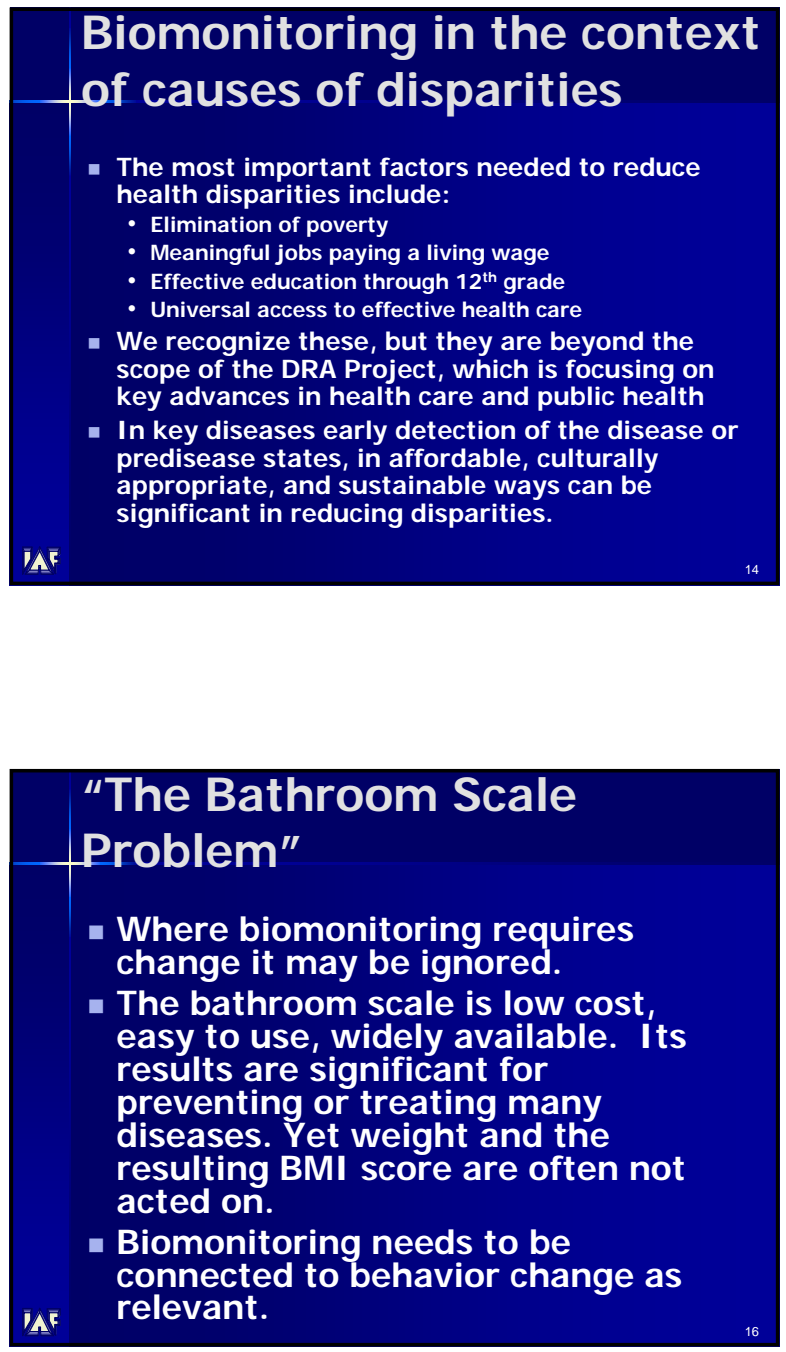

\section{Biomonitoring Futures Project}

- Focus of the project:

- Cancer (esp. breast, lung \& colon)

- Diabetes

- Prevention/Healthy Living

- Findings of BFP Research, including

- Diabetes and Cancer 2015

- Health Information Systems 2015

- Emerging biomonitoring platforms

Papers available at www.altfutures.com/BFP 


\section{Disparities Reducing Advances Project}

\section{April 6, 2006 Alexandria, Virginia}

\section{The Future of Biom onitoring Platform $s$}
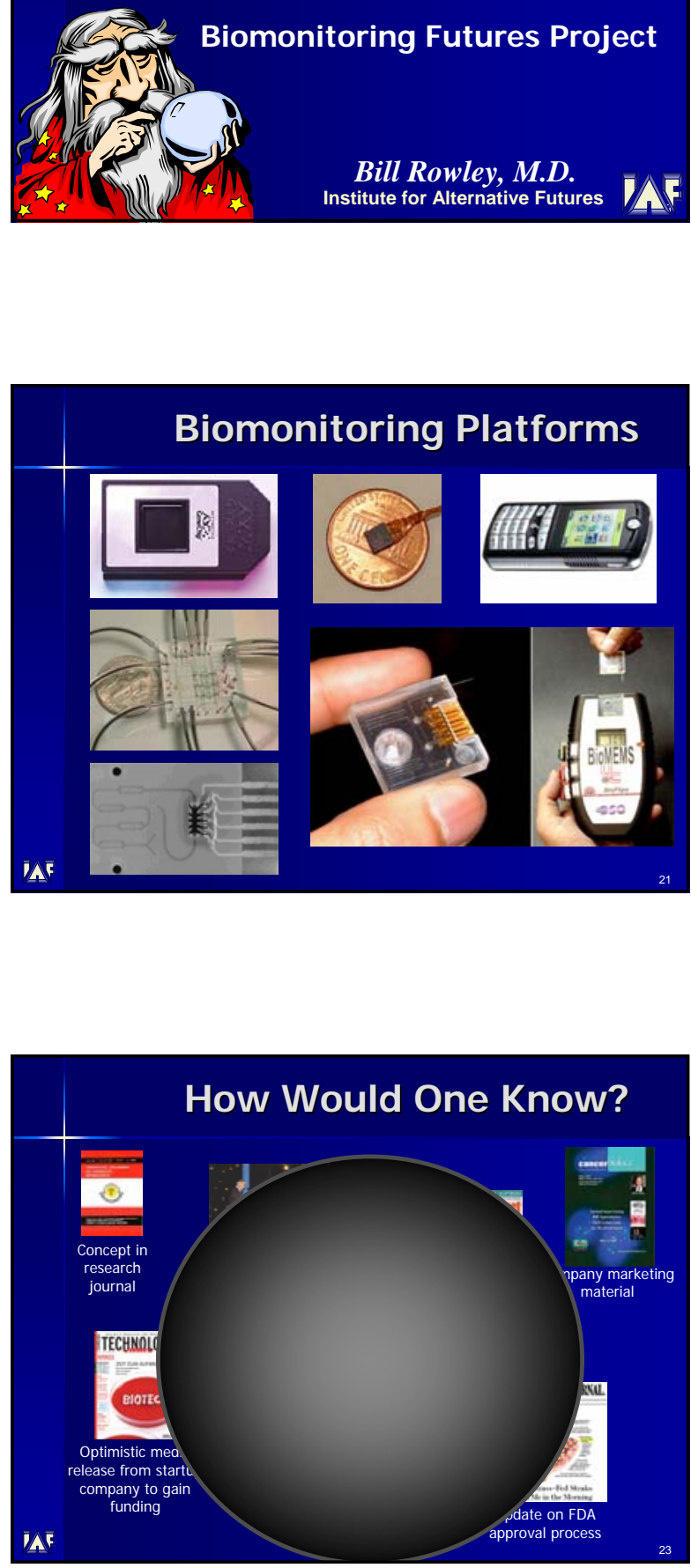
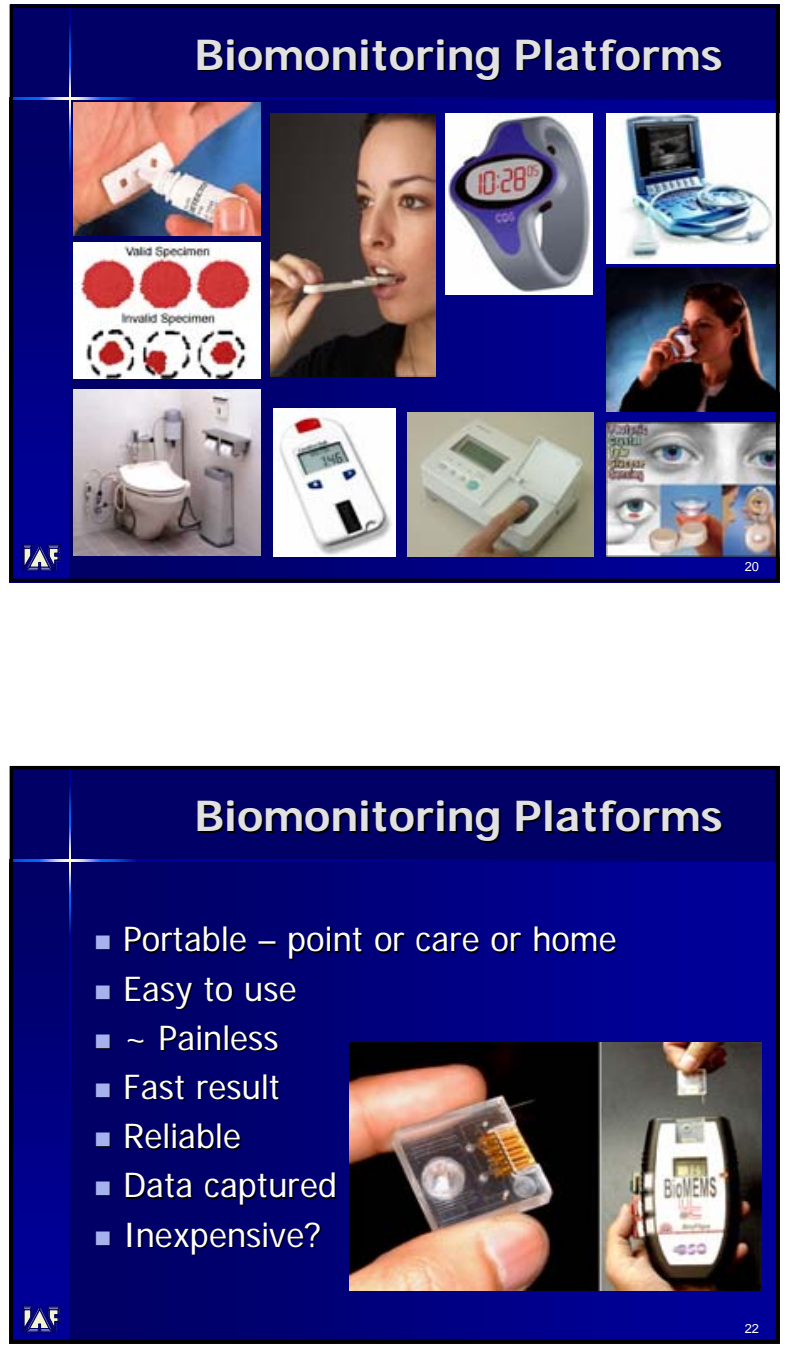

The hurdles

- Develop an idea to solve a problem

- Find the revenue

- Do the science $\&$ engineering

- Clinical trials - evidence of effectiveness

- Possibly regulatory approval

- Marketing

- Acceptance by physicians, payers, patients

DEF

Institute for Alternative Futures 


\section{Disparities Reducing Advances Project}

April 6, 2006 Alexandria, Virginia

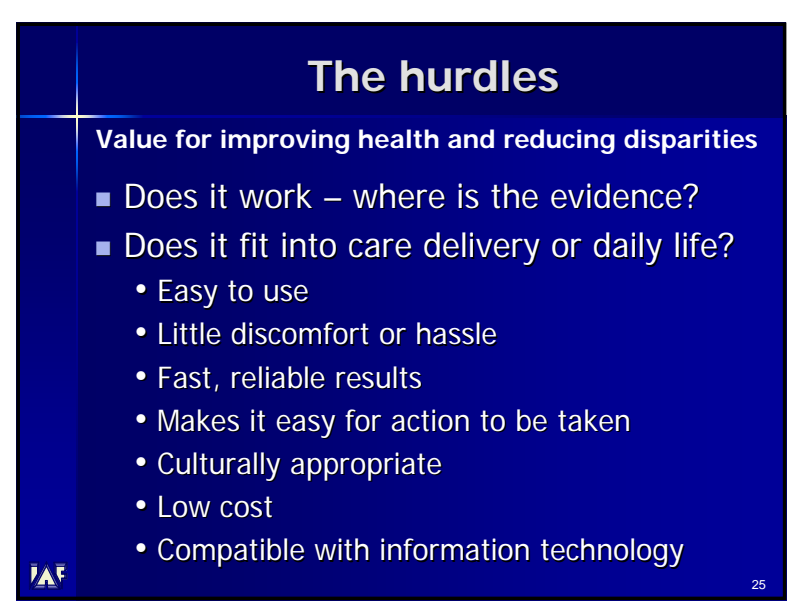

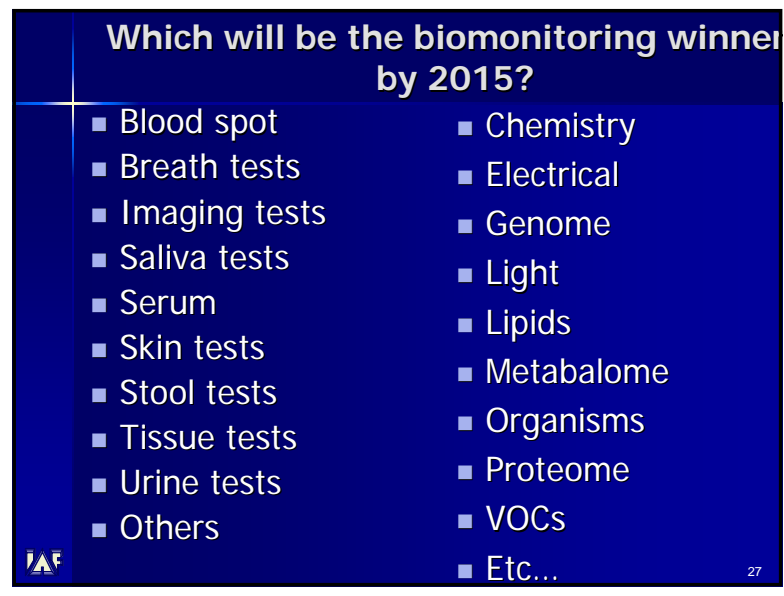

\section{NYC's Stealth Epidemic}

- 800,000 New Yorkers have diabetes

- Prevalence $30 \%$ higher than U.S.

- New cases occurring twice as fast

- One in three children will get diabetes - One in two for Latino and Black women

- North of $96^{\text {th }}$ street $20 \%$ have diabetes; South the prevalence is $1 \%$

- $30 \%$ don't know they have the disease - 2/3 who do know aren't doing enough to treat it

- Half of hospitalized patients are diabetic

LF
N.R. Kleinfield, Diabetes and Its Awful Toll Quietty Emerge as a Crisis, NYT, 19/06 and Living at the
Enicenter of Diabetes. Defiance and Despair. NYT. 1110/06
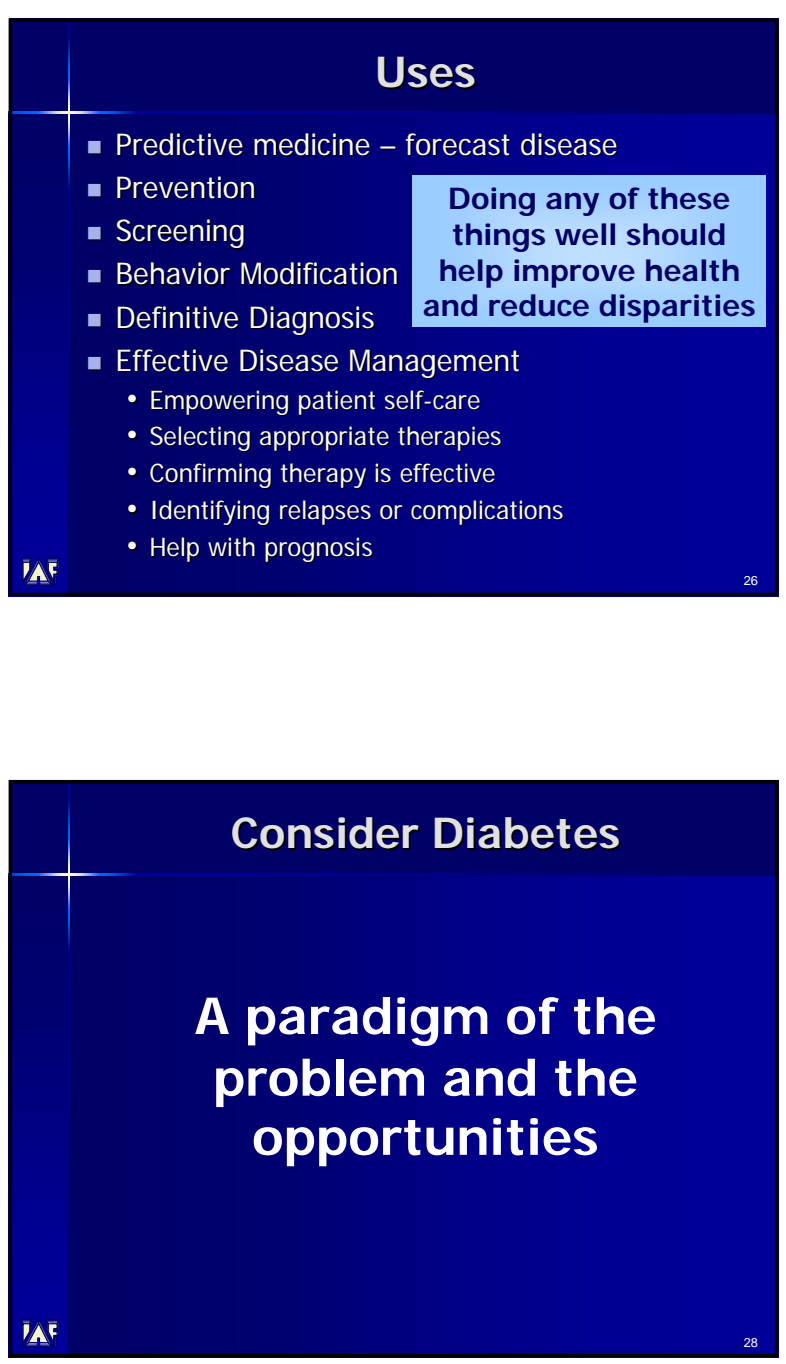

\section{Diabetes in the U.S. in 2025}

If we don't change...

- 50 million with diabetes

- 45 million pre-diabetics

- Annual new cases of serious morbidity:

- 70,000 blind

- 119,000 renal failure on dialysis

- 239,000 lower extremity amputations

- 622,000 deaths contributed by diabetes

- \$351 billion direct \& indirect cost

DFF Romey \& Bezold, Diabeles Forecasts to 2025 and Beyond: The Looming Cirisis Demands Change, 200530 


\section{Disparities Reducing Advances Project}

\section{April 6, 2006 Alexandria, Virginia}

\section{Diabetes in the U.S. in 2025}

Why is there an epidemic of diabetes?

- Diabetes is tied to the epidemic of obesity

- 2/3 of Americans are overweight; 1/3 obese

- Lifetime risk white men: women:

$$
\begin{array}{ll}
\text { - } 92 \% \text { overweight } & -81 \% \text { overweight } \\
\text { - } 49 \% \text { obese } & -48 \% \text { obese }
\end{array}
$$

- $15 \%$ adolescents overweight

- $23 \%$ of Blacks \& Hispanics

- $50 \%$ of childhood diabetes now type 2

\section{Preventing Diabetes?}

\section{Prevention}

\section{Million with Pre-diabetes}

- 50\% will develop diabetes within 10 yrs

- Diabetes can be prevented $58 \%$ of time

- Loss 8-15 pounds

- 30 minutes of activity 5 times a week

- Yet usually not screened and little urgency in managing prediabetes

$\bar{\Delta} \mathbf{F}$

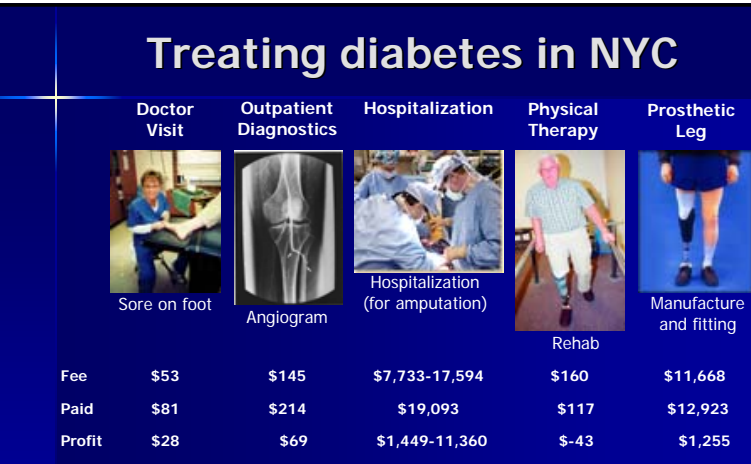

System encourages people to get sick and then providers get paid for treating them!

LF

\begin{tabular}{|c|c|c|c|}
\hline \multicolumn{4}{|c|}{ Diabetes in the U.S. in 2025} \\
\hline & $\begin{array}{c}\text { Risk of } \\
\text { Diabetes }\end{array}$ & $\begin{array}{c}\text { Life Years } \\
\text { Lost } \\
\text { (Onset @ 30) }\end{array}$ & $\begin{array}{c}\text { Quality } \\
\text { Adjusted Life } \\
\text { Years Lost }\end{array}$ \\
\hline \multicolumn{4}{|l|}{ MALE } \\
\hline White & $27 \%$ & 13 yrs & 22 yrs \\
\hline Black & $40 \%$ & 17 yrs & 24 yrs \\
\hline Hispanic & $45 \%$ & 15 yrs & 24 yrs \\
\hline \multicolumn{4}{|l|}{ FEMALE } \\
\hline White & $31 \%$ & 16 yrs & 25 yrs \\
\hline Black & $49 \%$ & 20 yrs & 28 yrs \\
\hline Hispanic & $53 \%$ & 14 yrs & 25 yrs \\
\hline & & ted Satere & 03 \\
\hline
\end{tabular}

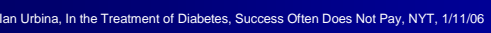

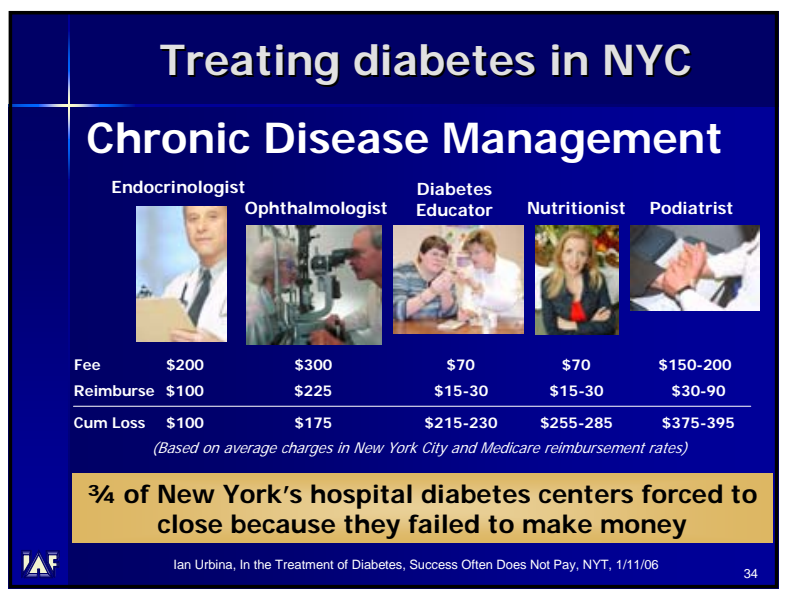

\section{Treating diabetes in NYC}

\section{9-12 year delay in diagnosis}

$20 \%$ already have eye, nerve or kidney damage by time diagnosed $\mathbf{9 0 \%}$ of diabetics don't know their HAlc scores

Lack of urgency - takes $\sim 6$ months to address abnormal HAlc Medicaid pays for one visit a day; nurse call for checkup not paid; insurance pays for 1 test strip/ day 


\section{Disparities Reducing Advances Project}

April 6, 2006 Alexandria, Virginia
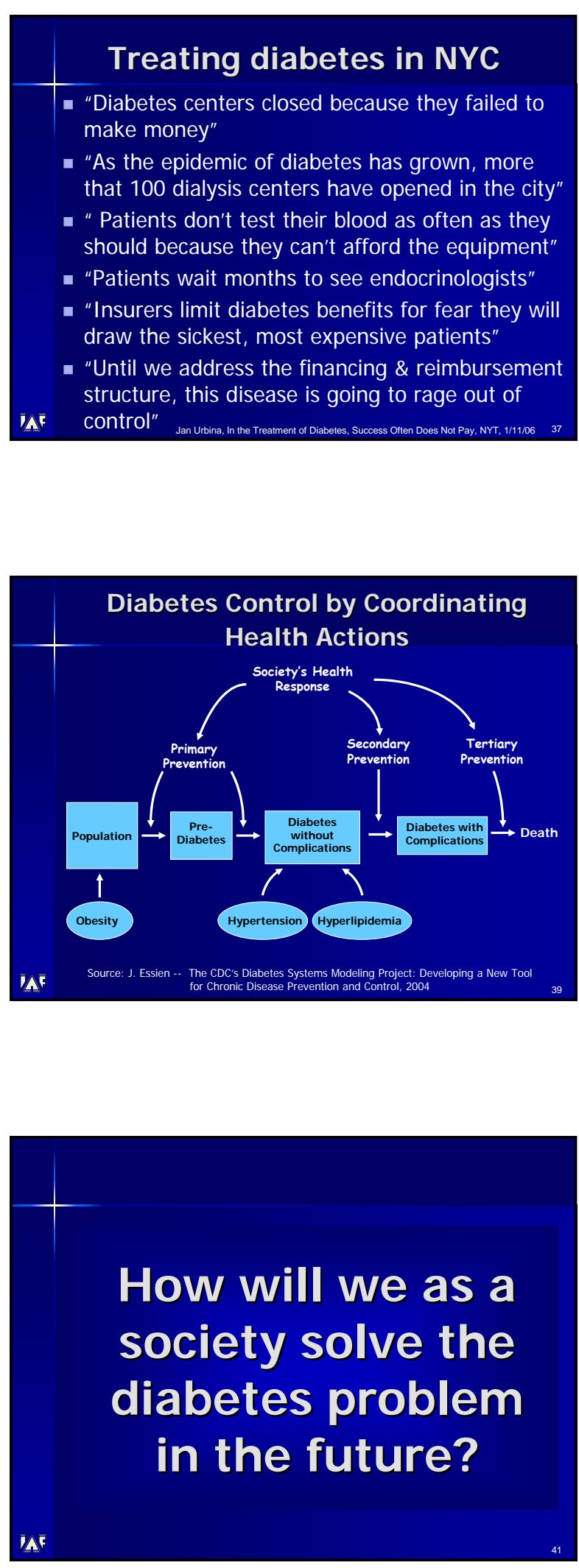

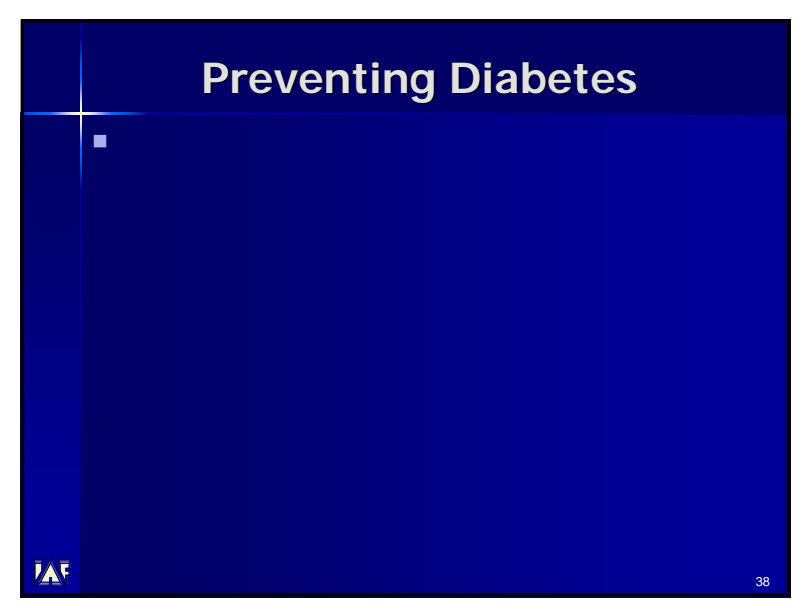

\section{Preventing Diabetes}

The diabetes prevention trial of NIH showed that $\mathbf{5 8 \%}$ of individuals at high risk for diabetes could prevent conversion to Type 2 diabetes (a lifelong chronic disease with complications such as blindness, amputations and kidney failure.)

$\overline{L F}$

\section{The History of Health 2025}

- Prevention

- Screening

- Behavior modification

- Effective management of chronic diseases

- Empowered patient self-care

- Advances in biotechnology and information

- Personalized medicine

- Access to care

- Address the obesogenic environment

IAF

- Address social determinants of health 


\section{Disparities Reducing Advances Project}

\section{April 6, 2006 Alexandria, Virginia}

\section{Type 2 diabetes}

\begin{tabular}{|l|l|}
\hline \multicolumn{1}{|c|}{$\begin{array}{c}\text { Component of } \\
\text { Management }\end{array}$} & \multicolumn{1}{c|}{ Role for Biomonitoring } \\
\hline Forecast Risk & $\begin{array}{l}\text { Gene patterns, including mitochondrial } \\
\text { genes Possibly protein or metabolic patterns }\end{array}$ \\
\hline Prevention & $\begin{array}{l}\text { Information and coaching for healthy living } \\
- \text { diet and exercise }\end{array}$ \\
\hline Screening & $\begin{array}{l}\text { Identify prediabetes, diabetes, dyslipidemia } \\
\text { hypertension }\end{array}$ \\
\hline Behavior Modification & How well controlling HgA1c, lipids, BP \\
\hline Disease Management & $\begin{array}{l}\text { Easy testing with rapid results at point of } \\
\text { care }\end{array}$ \\
\hline Patient self-care & $\begin{array}{l}\text { Biomonitoring to help management - } \\
\text { wireless capture and longitudinal record }\end{array}$ \\
\hline
\end{tabular}

\section{Glucose Biomonitoring}

\section{NSTI Nanotech 2006}

- Polymerized Crystalline Colloidal Arrays Photonic Cosmetic Contact Lenses

- Detection of Glucose and other Biomedical Analytes on Biosensor Surfaces using Fractal Analysis

- A glucose Biosensor Encapsulated in Erythrocytes

- Carbon Microstructures for Glucose Biosensor

- New Biosensor Technologies: Your Personal, Portable and Always On-call Physician

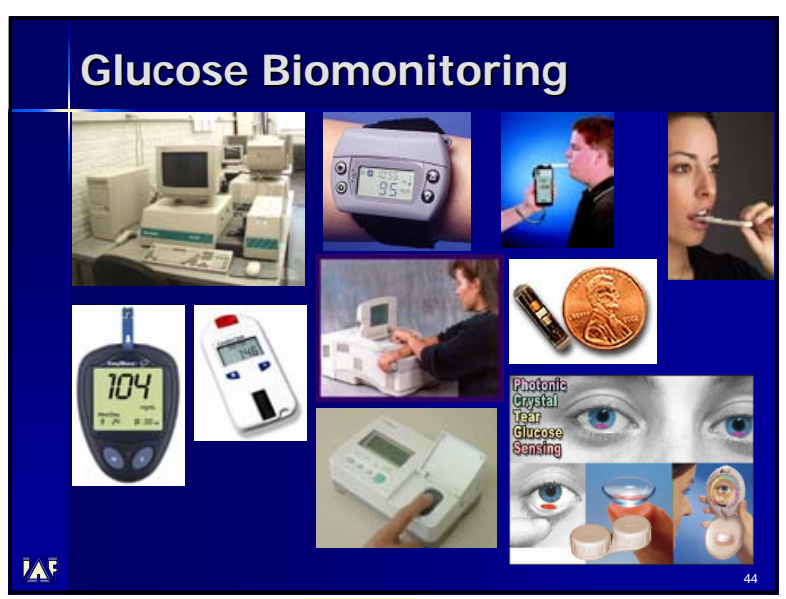

\section{Glucose Biomonitoring}

\section{I am convinced we will have a} noninvasive glucose monitor before 2015

But I do not know which platform technologies will succeed Bill Rowley, MD, IAF

Whichever becomes avallable, we must make sure it is leveraged to inf reduce health disparities

\section{Biomonitoring \& Behavior}

Games \& Reinforcement
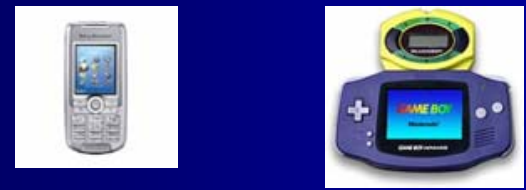

How do we leverage biomonitoring to improve compltance and change behavior?
Bill Rowley, M.D.
The Future of Biom onitoring for Cancer

Biomonitoring Futures Project Institute for Alternative Futures 


\section{Disparities Reducing Advances Project \\ April 6, 2006 Alexandria, Virginia}

\section{Cancer Burden}

- Leading cause of death for those $<85$

- $1 / 2$ of men and $1 / 3$ of women will develop cancer during lifetime

- 1,373,000 new cases of cancer this year

- Death rates now dropping 1\% per yr

- Still 570,300 will die of cancer this year

- Lung cancer

- 172,500 new cases expected in 2006

- Biggest killer - 163,500 deaths in 2006

BAE

- Incidence declining for men, level for women

\section{Cancer Burden}

- Breast cancer

- Most common female cancer - 211,000

- Second leading cause of death - 40,400

- Incidence $\uparrow 0.3 \%$ per year

- Mortality $\downarrow 2.4 \%$ per year

- Colon cancer

- Third most common - 145,300

- Second most deadly - 56,300

- Incidence and death rates declining

金

\section{Screening Compliance}

- Mammogram

- $61.5 \%$ of women over 40 had one last year

- $43 \%$ if didn't finish high school

- $28.9 \%$ if no insurance coverage

- Stool Fecal occult blood testing

- $19 \%$ over $50 \mathrm{y} / 0$ had test last year

- $9.3 \%$ if no health insurance $(<65 \mathrm{y} / 0)$

- Colonoscopy in past 5 years

- $45.6 \%$ of over $50 \mathrm{y} / 0$ had test

- $18.8 \%$ if no health insurance $(<65 \mathrm{y} / 0)$

DEF American Cancer Sociery Guidelines tor the Early Detection of Cancer, 2006

\section{Protein and Gene Biomarkers}

- Gene variations associated with higher risk

- Single genes - BRCA1 \& BRCA2

- Genomic fingerprints

- DNA methylation - 50 genes where plays role in cancer

- Abnormal genes in established cancers presence of epidermal growth factor receptor mutations

- Improved patient education

- New biomarkers that are less embarrassing or uncomfortable

- Inexpensive screening biomonitoring tests 


\section{Disparities Reducing Advances Project}

April 6, 2006 Alexandria, Virginia

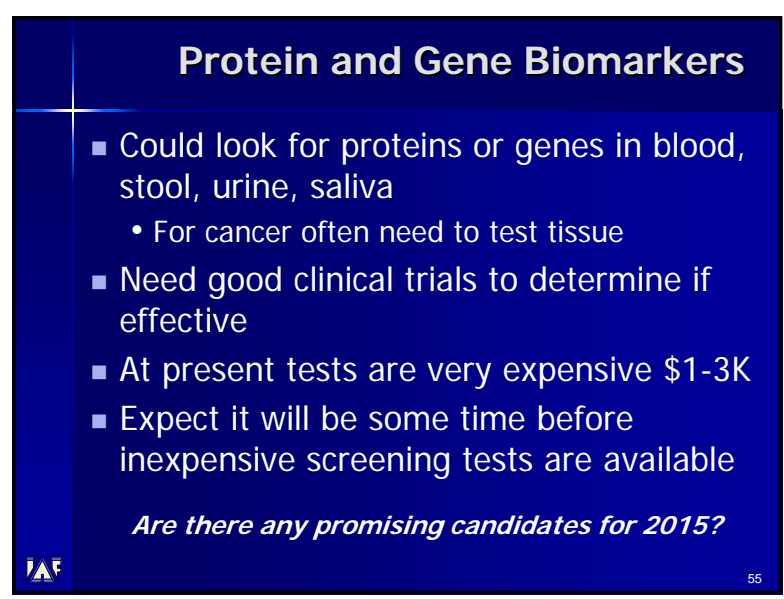

\section{Biom onitoring for Prevention \& Healthy Living}

Biomonitoring Futures Project

Craig Bettles

Institute for Alternative Futures
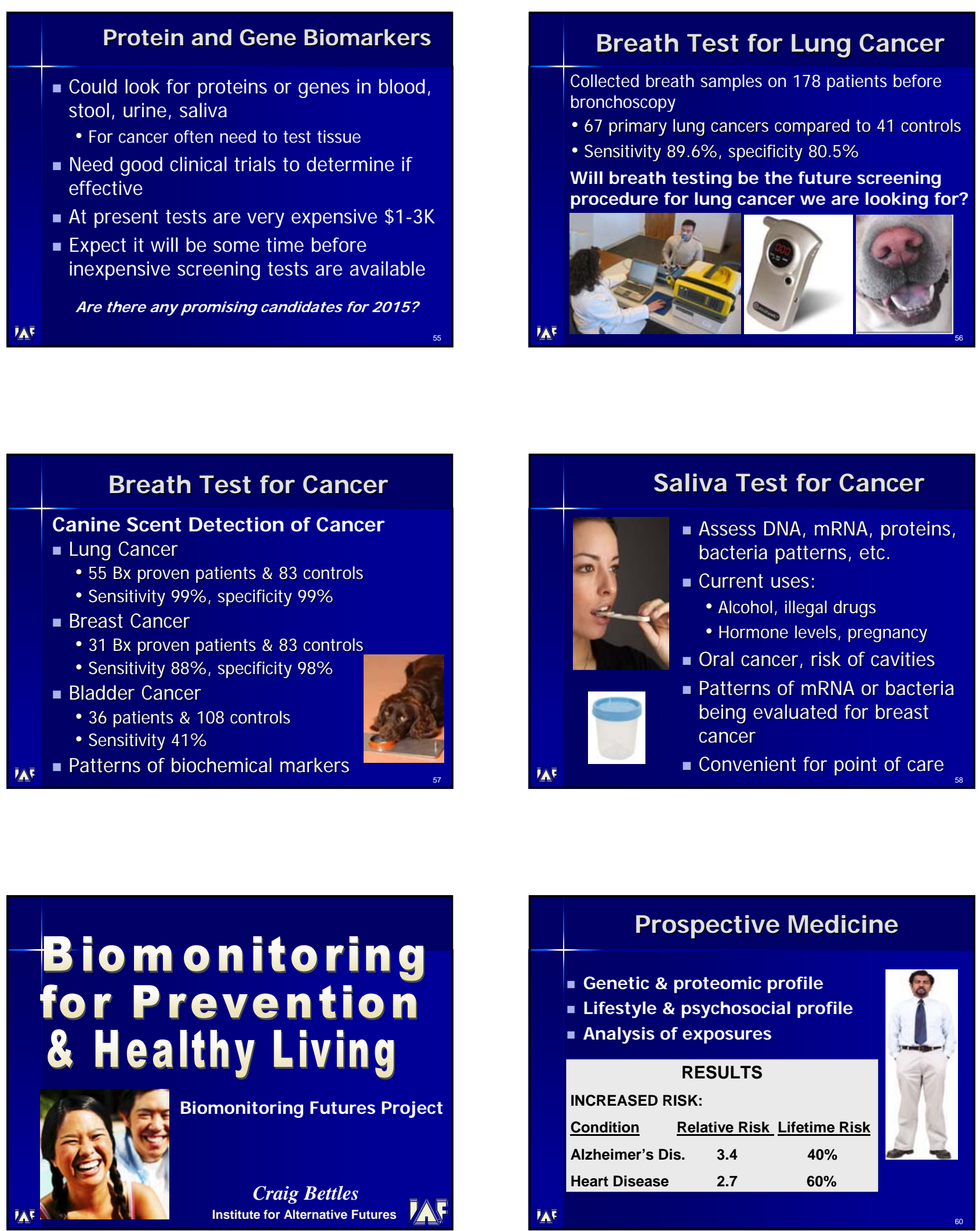

Institute for Alternative Futures 


\section{Disparities Reducing Advances Project \\ April 6, 2006 Alexandria, Virginia}
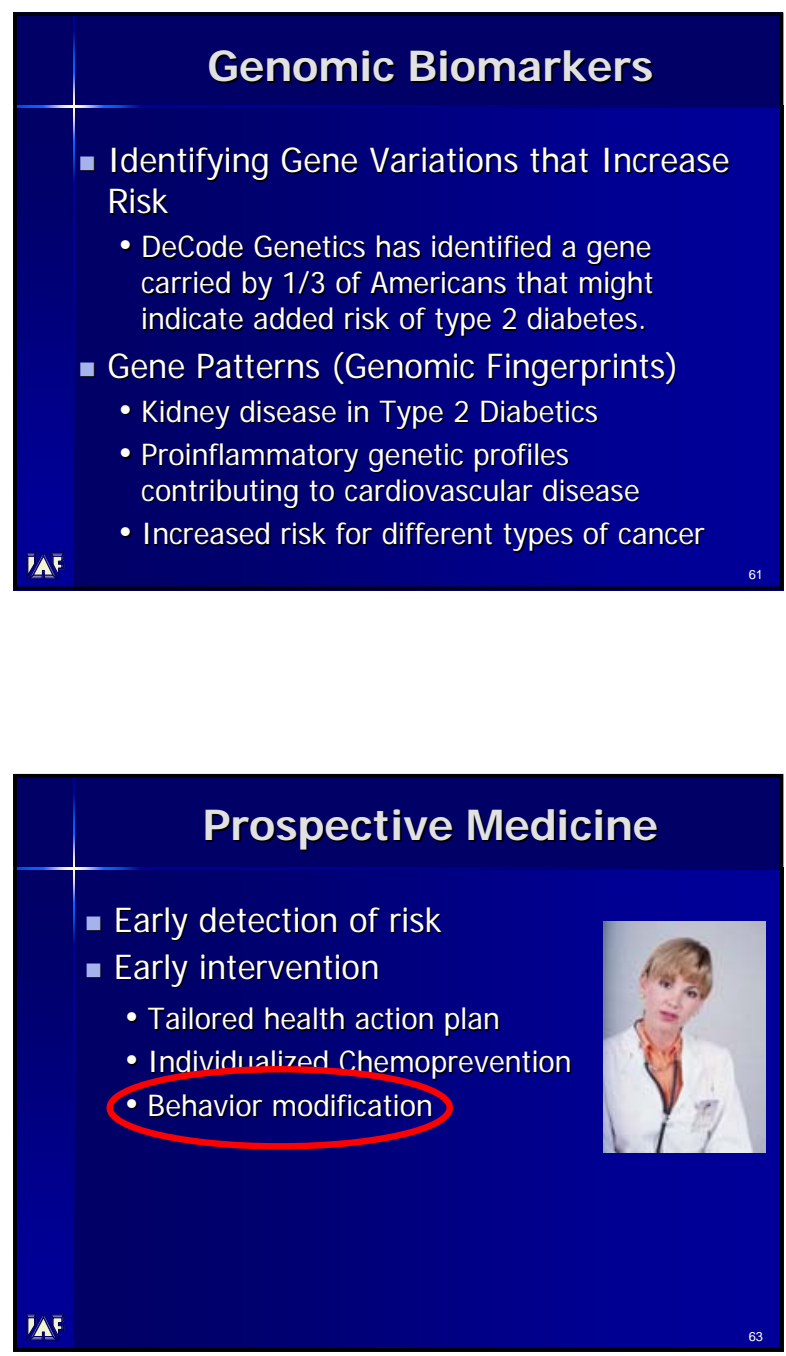

Biomonitoring for Healthy Living

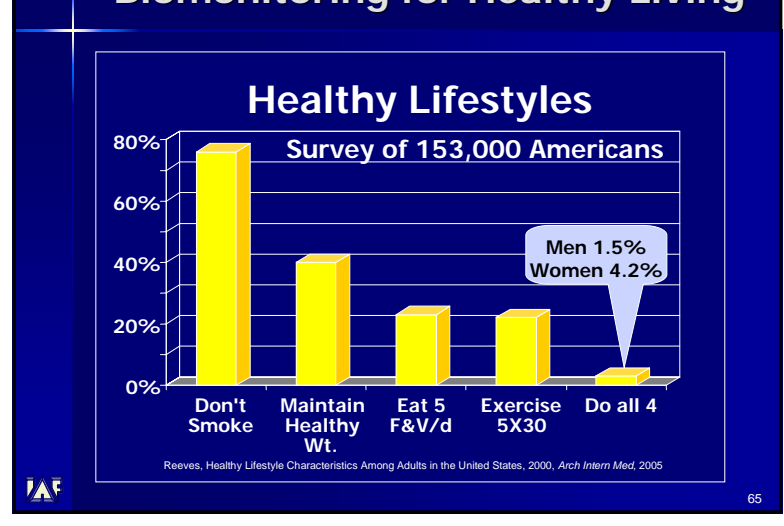

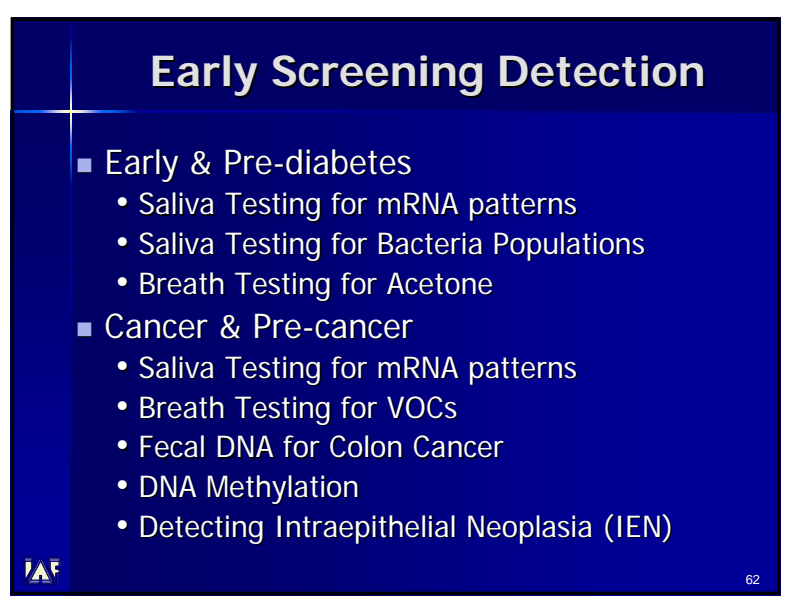
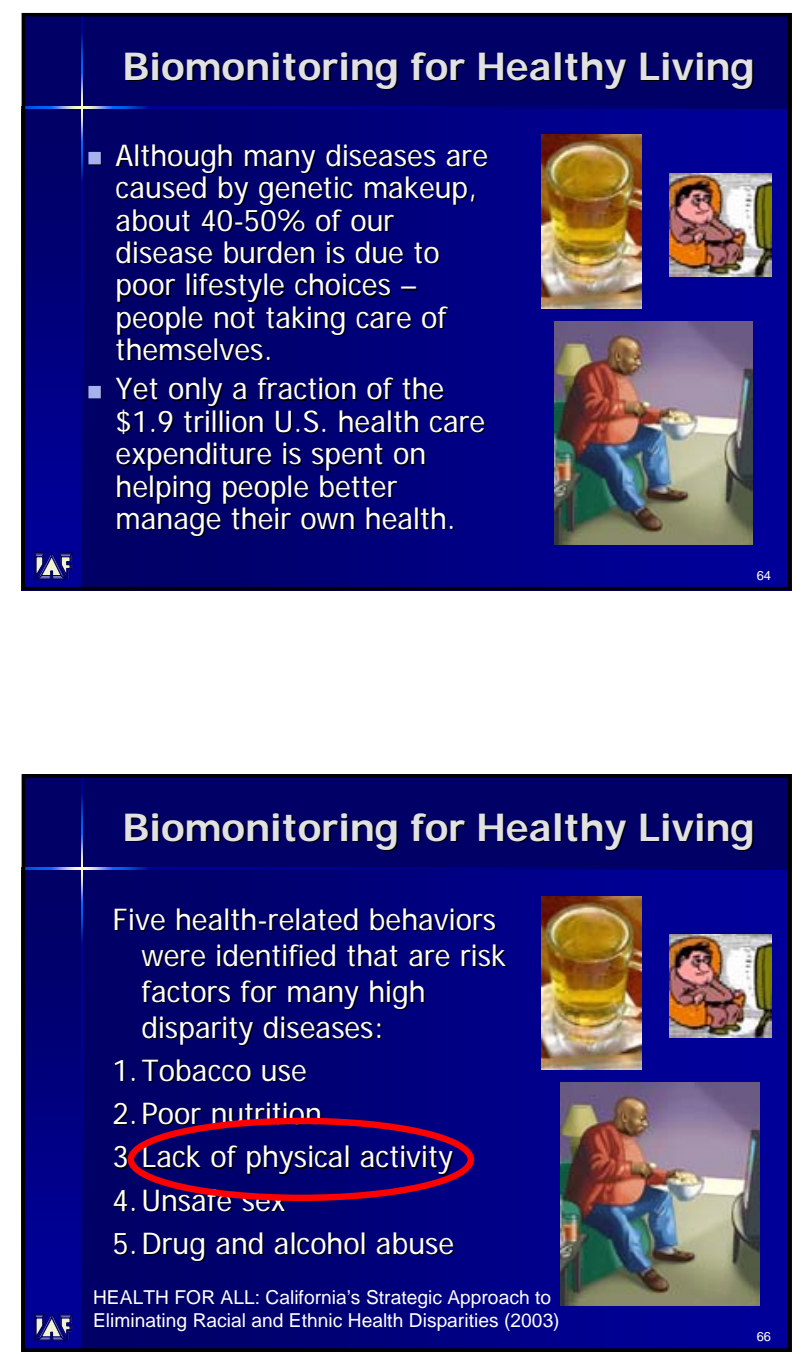

Institute for Alternative Futures 


\section{Disparities Reducing Advances Project}

April 6, 2006 Alexandria, Virginia
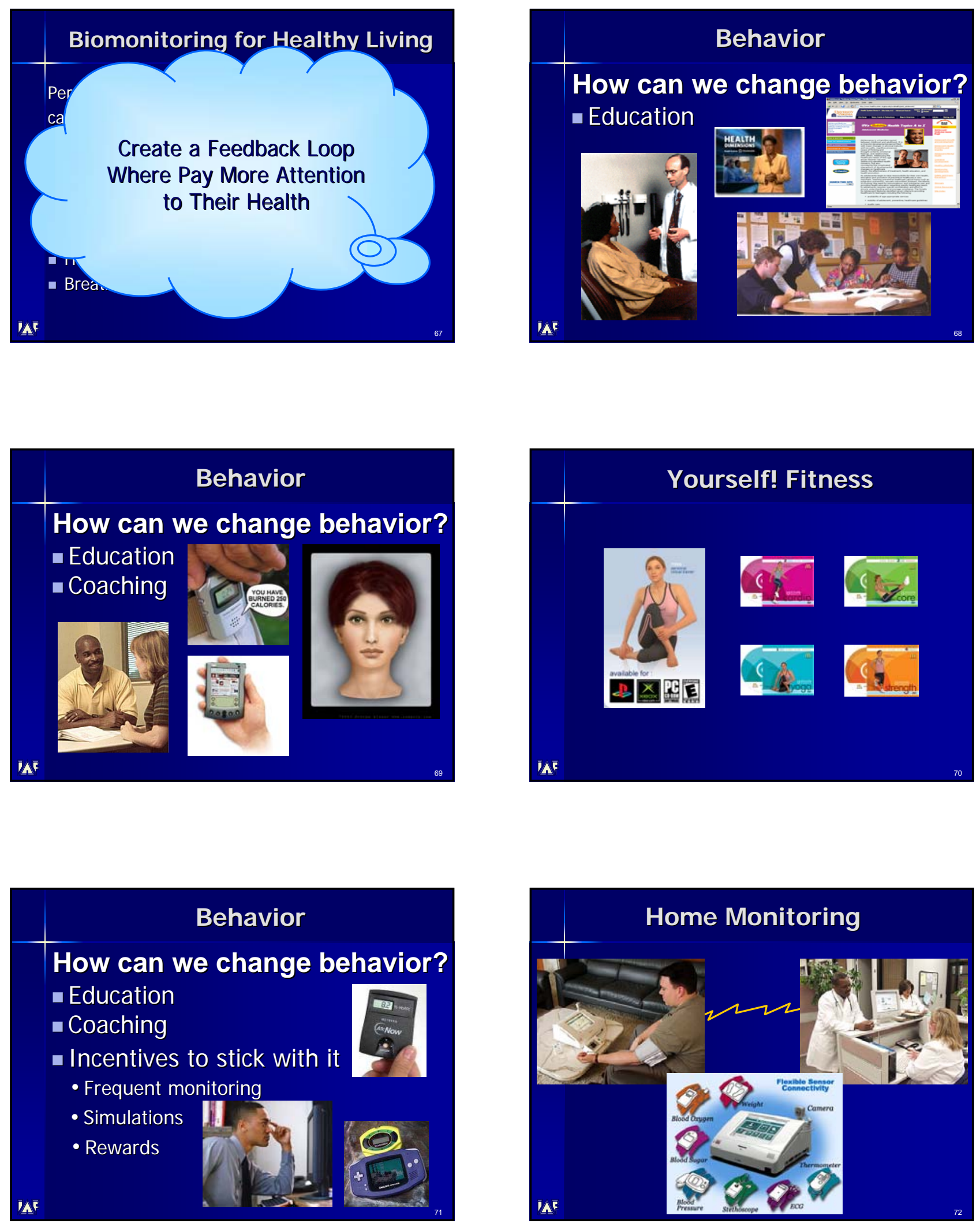


\section{Disparities Reducing Advances Project \\ April 6, 2006 Alexandria, Virginia}

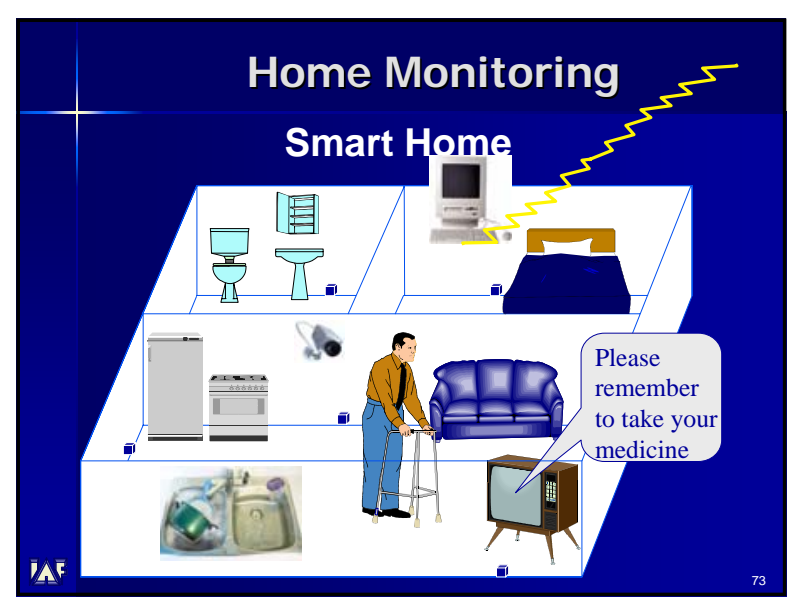

\section{Promising Biomonitoring Advances}

Promoting Biomonitoring as Disparity Reducing Advances:

Opportunities and Recommendations for the Field

From Biomonitoring Futures Project

$\overline{L F}$

Developing Biomonitoring to Reduce Disparities: Recommendations

1. HRSA and CMS should enhance partnerships for evaluating the intersection of biomonitoring platforms, specific disease biomarkers, and $\mathrm{CHCs}$

2. Clinical Director's Network and other appropriate groups should help design \& implement controlled studies of effectiveness of biomonitoring systems in CHCs as well as diffusing best practices

3. Encourage major federal agencies such as DoD, NIH and VA to develop a more coherent early stage funding programs based around $\bar{\Delta} \bar{F}$

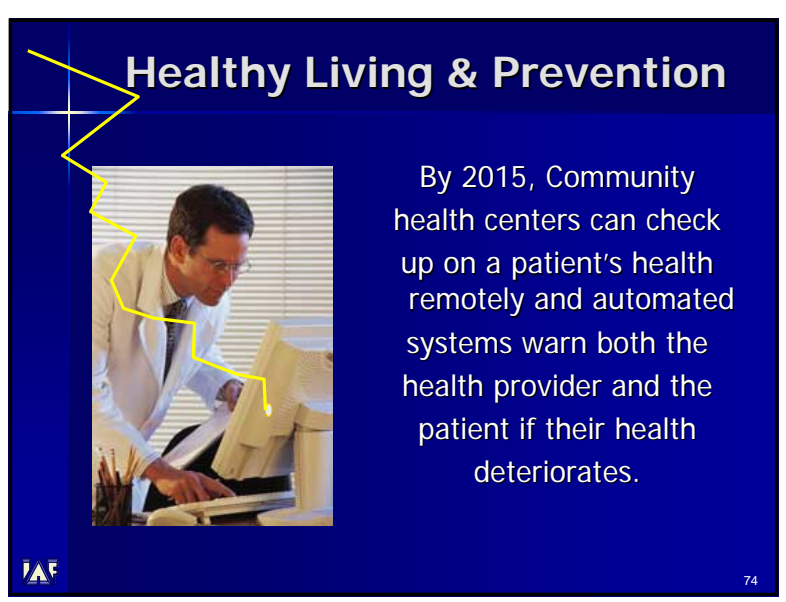

Promising Biomonitoring Advances

Key Opportunities for Biomonitoring to Reduce Disparities:

1. Support continuous, passive monitoring for healthy living \& prevention

2. Develop an indwelling closed loop insulin pump and biomonitoring system

3. Focus on early detection for cancer through early screening using blood as a platform

4. Support the use of biomonitoring to change behavior, upstream, at the community and national level

IAF

Developing Biomonitoring to Reduce

Disparities: Recommendations

4. Work with industry associations, such as PhARMA and NEMA on their members' biomonitoring activity and disparity reducing opportunities

5. The FDA should encourage testing and evaluation of biomonitoring devices among populations with less access and resources

$\overline{A^{F}}$ 


\section{Disparities Reducing Advances Project}

April 6, 2006 Alexandria, Virginia

Developing Biomonitoring to Reduce Disparities: Recommendations

6. Enhance the ability of CHCs and others to design, deploy and evaluate experiments/tests of potential biomonitoring advances

7. Provide forecasts or estimates of platforms under development or in consideration as well as potential disruptive innovations

8. Identify specific forums to develop and share information on biomonitoring for disparity reduction

\section{The DRA Project 2006}

- Pursuing Biomonitoring and other promising disparity reducing advances

1. Community Health/ Prevention Approaches

- Reinforcing higher physical activity levels and safe, walkable communities

- Creating healthy eating programs in schools, vending machines and fast food restaurants.

- Fostering healthy eating by families - affordable healthy food choices in grocery stores and shops

- Developing culturally appropriate healthy menus

- I mplementing health education and literacy programs in schools and low income communities

- Building social capital and relevant norms

- Using community workers (e.g. barbers and hair dressers) as health coaches, lay health advocates and prayer buddies

- I mplementing church based screening and prevention programs
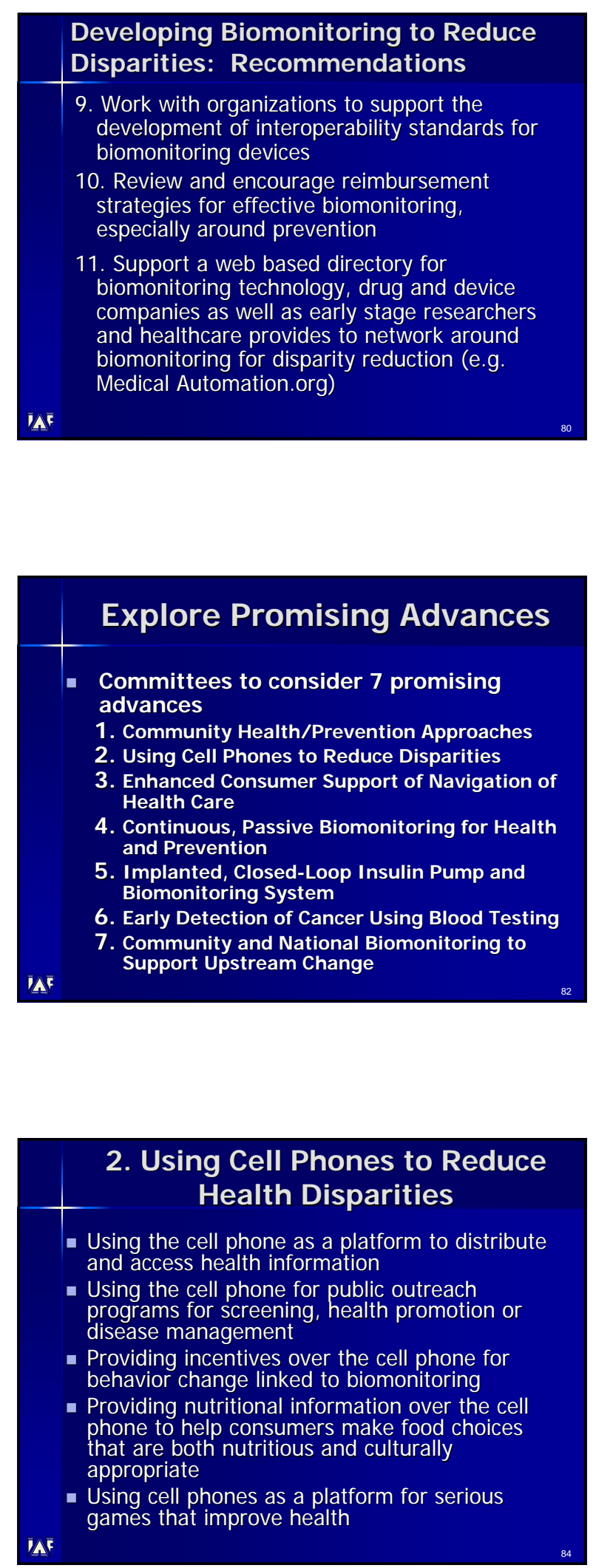


\section{Disparities Reducing Advances Project}

April 6, 2006 Alexandria, Virginia

\section{Enhanced Consumer Support of} Navigation of Health Care

- A database of common definitions and terms

- Simple and clear documentation to point patients in the right direction

- Identifying and supporting ongoing sources of payment for consumer navigation

- Best practices on how to harness and enhance informal approaches to consumer navigation

- An electronic "Health Compass" for individuals for navigating health services

$\bar{\Delta} \bar{F}$

\section{Criteria Committee}

The DRA Project has developed a set of criteria for identifying the most important advances. These criteria will be explored and applied to the promising advances and the the other specific advances in the areas listed above.

$\Delta$

\section{DRA in 2006}

- Summer of 2006

- Continue Scanning Activities

- Conduct committees on 7 promising advances and applying the criteria

- Fall of 2006

- Second Partners Meeting on Sept. 13th

- Select and Report on Advances and Opportunities

- Develop Forecasts for Advance Areas
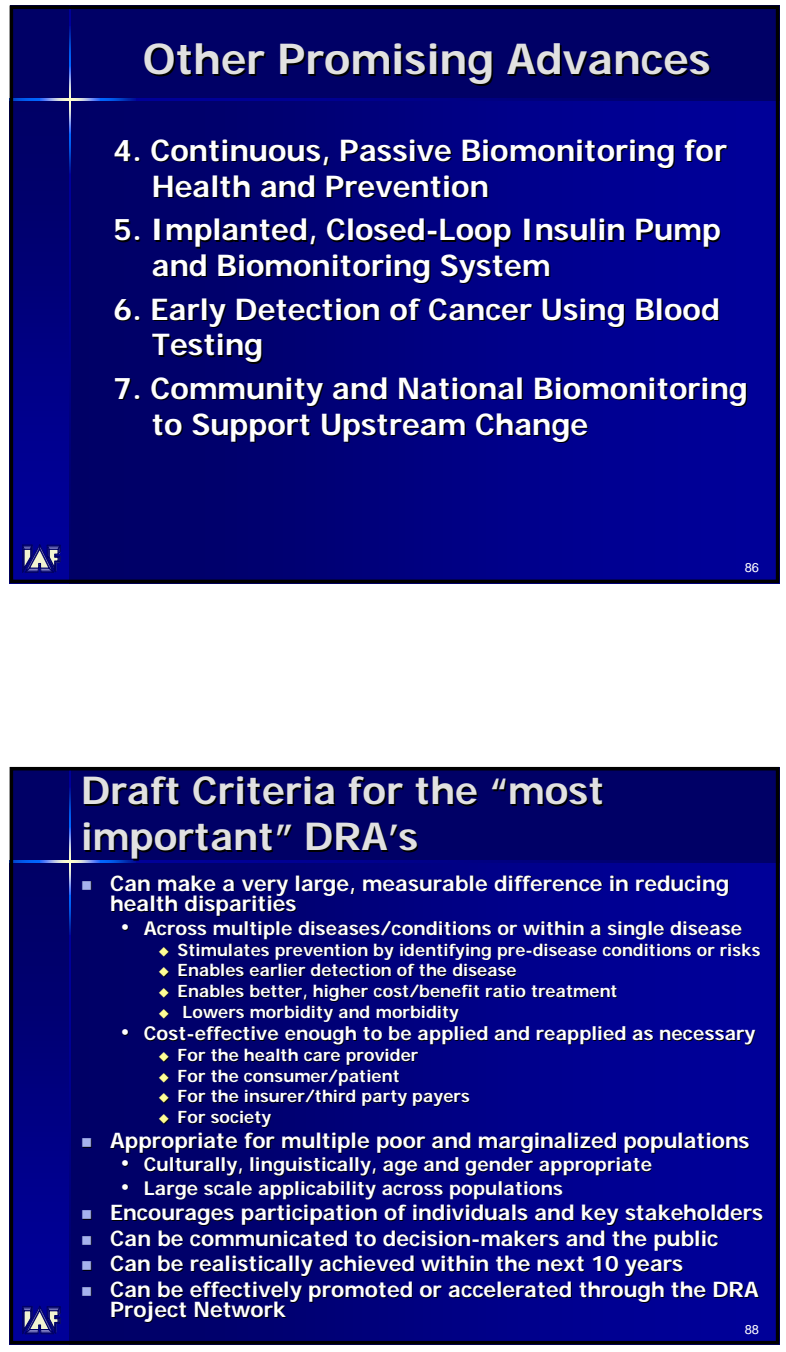

\section{DRA in $2007 \& 2008$}

- Continue to Build the Partner Network

- Pursue and Develop Specific Projects Around Promising Advances \& Opportunities

- Identify Design Changes in Advances Needed to Make Them Relevant to Underserved Communities

- Increase Deployment of Selected Advances Through the Partner Network

- Increase Deployment of Selected Advances By Targeting Decision Makers in Healthcare, Industry and Government

$\overline{A F}$ 


\section{Disparities Reducing Advances Project \\ April 6, 2006 Alexandria, Virginia}

\section{J oining the DRA Project}

- The information presented here is available at

- www.altfutures.com/dra

- $\underline{w w w . a l t f u t u r e s . c o m / b f p}$

- If you and your organization are interested in becoming a DRA Project Partner - contact Clem Bezold or Sandra Tinkham at IAF (stinkham@altfutures.com).

in $\bar{A}$ 